Research Article

\title{
In-vivo Antidiabetic Activity of Novel N-substituted Thiazolidinedione Derivative in Streptozotocin Induced Diabetic Albino Wister Rats
}

\author{
Meeramol C Chellappan*, Christy K Jose, Shilpa S Kurup \\ Department of Pharmaceutical Chemistry, Pushpagiri College of Pharmacy, Thiruvalla, Kerala, India. \\ *Corresponding author's E-mail: meerachennamattam@gmail.com
}

Received: 18-10-2020; Revised: 24-12-2020; Accepted: 30-12-2020; Published on: 15-01-2021.

\begin{abstract}
The present study was focused to evaluate in-vivo anti-diabetic activity of novel $\mathrm{N}$ - substituted thiazolidinedione derivative in the streptozotocin diabetic rats. Diabetes was induced in overnight fasted rats by single intraperitoneal injection of streptozotocin $(60$ $\mathrm{mg} / \mathrm{kg}$ ). Blood glucose levels were measured 7 days after the streptozotocin injection and blood glucose levels and body weight are monitored on $0^{\text {th }}, 1^{\text {st }}, 7^{\text {th }}$ and $15^{\text {th }}$ day. The statistical data indicated that the novel $\mathrm{N}$ - substituted thiazolidinedione derivative significantly decrease the level of blood glucose in streptozotocin induced rats. It was found that novel derivative showed highly significant decrease in the blood glucose levels when compared to the control STZ induced diabetic animals which was compared with the standard drug Pioglitazone $(36 \mathrm{mg} / \mathrm{kg})$.
\end{abstract}

Keywords: Thiazolidinedione, Pioglitazone, Streptozotocin induced diabetic activity, Diabetes Mellitus.

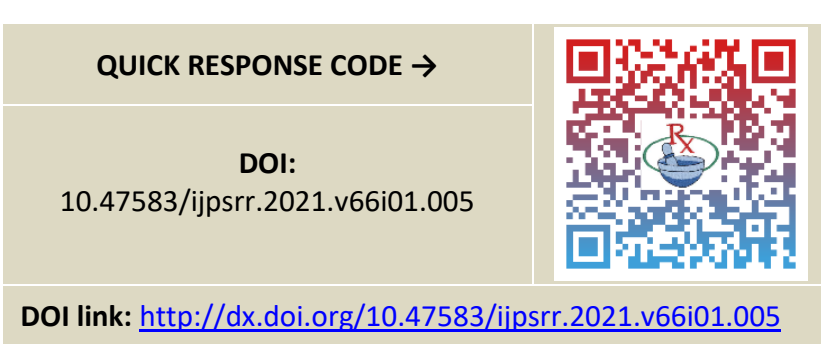

\section{INTRODUCTION}

ccording to WHO reports; 30 million people were affected from diabetes in 1985 which increased to 185 million in 2000 and expected to double by 2030. These epidemic calculations put a demand towards the development of more potent and efficacious agents to control diabetes. Many drugs have been approved from thiazolididione class for the treatment of diabetes like Rosiglitazone, Pioglitazone, Ciglitazone and many more. Though they show additive effects, they are prone to show toxicity.

2, 4-thiazolidinedione ${ }^{1}$ consists of a five membered thiazolidine ring with carbonyl group at 2 and 4 positions. Variable substitutions occur at 3 and 5 positions, but substitution at 2 cause changes in structure and properties of thiazolidinedione.

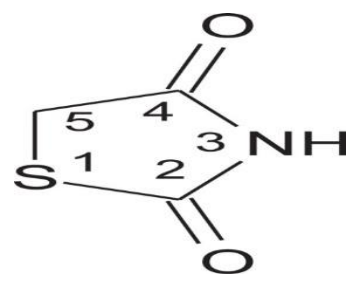

Thiazolidinediones are found to exhibit wide range of pharmacological activities such as anti-hyperglycaemic, antiviral, anticancer, antimicrobial, aldose reductase inhibitors, etc. The biological activities associated with TZD derivatives are due to the binding of molecule with PPAR gamma (Peroxisome Proliferators Gamma Activated Receptor).

\section{MATERIALS AND METHODS}

\section{Methodology for Synthesis ${ }^{2}$}

\section{Step 1: Synthesis of Thiazolididione}

In a $250 \mathrm{ml}$ three-necked flask, a solution containing $0.6 \mathrm{~mol}$ of chloroacetic acid in $60 \mathrm{~mL}$ of water and $0.6 \mathrm{~mol}$ of thiourea was dissolved in $60 \mathrm{~mL}$ of water. The mixture was stirred until the white precipitate was formed. $60 \mathrm{Ml}$ of conc. hydrochloric acid was slowly added to the contents of flask. After dissolving the precipitates, reaction mixture was stirred and then refluxed for $10-12 \mathrm{hrs}$ at $100-110^{\circ} \mathrm{C}$, on cooling the contents of flask were solidified to a mass of clusters of white needles. The product was filtered and washed with water to remove traces of hydrochloric acid and dried. It was recrystallised from ethanol.

\section{Step 2: Synthesis of Thiazolidinedione Derivative}

4-(benzyloxy) benzaldehyde (0.2M) in DMF was added into a solution of 2, 4-thiazolidinedione (0.1M) in DMF, under stirring. The reaction mixture was stirred at room temperature for $15 \mathrm{~min}$. To the solution, diethylamine DMF was added drop wise and reflux for 12 hours. After 12 hours the reaction mixture was poured in an ice cold water and filtered off and wash with hot water. Finally it was recrystallised from chloroform, ethanol to give final compound.

\section{Animals}

Albino rats (Wistar strain) were used to carry out the activities. The animals had free access to standard commercial diet and water ad libitum and were housed in 
cages under standard laboratory conditions i.e.; 12:12 hour light or dark cycle at $25 \pm 20^{\circ} \mathrm{C}$. The experiments were carried out as per the guidelines of CPCSEA, New Delhi, India and approved by the Institutional Animal Ethical Committee (IAEC Number.: PCP/IAEC/2019-1/1).

\section{In- vivo anti-diabetic activity}

\section{Streptozotocin induced Diabetic study ${ }^{3}$}

Diabetes was induced in overnight fasted rats by single intraperitoneal injection of streptozotocin $(60 \mathrm{mg} / \mathrm{kg}$ ). Blood glucose levels were measured 7 days after the streptozotocin injection and rats with fasting blood glucose levels greater than $200 \mathrm{mg} / \mathrm{dl}$ were considered to be diabetic used in the experiment.

\section{Experimental design}

5 groups of rats were used to study and each group consists of 6 rats.

- Group I: untreated group (normal control).
- Group II: Positive control (0.1 M citrate buffer is given).

- Group III: Disease control induced with $60 \mathrm{mg} / \mathrm{kg}$ of Streptozotocin (I.P).

- Group IV: Diabetic rats were treated with TZD D9 60 $\mathrm{mg} / \mathrm{kg}$.

- Group V: Diabetic rats were treated with Pioglitazone $36 \mathrm{mg} / \mathrm{kg}$ body weight.

Treatment of experimental animals with synthesised TZD derivatives was initiated after 7 days streptozotocin injection, and blood glucose levels and body weight are monitored on $0^{\text {th }}, 1^{\text {st }}, 7^{\text {th }}$ and $15^{\text {th }}$ day.

\section{Statistical analysis}

Value are expressed as mean \pm SEM from six observations. Statistical analysis was done by one-way anova followed by dunnett's t-test.

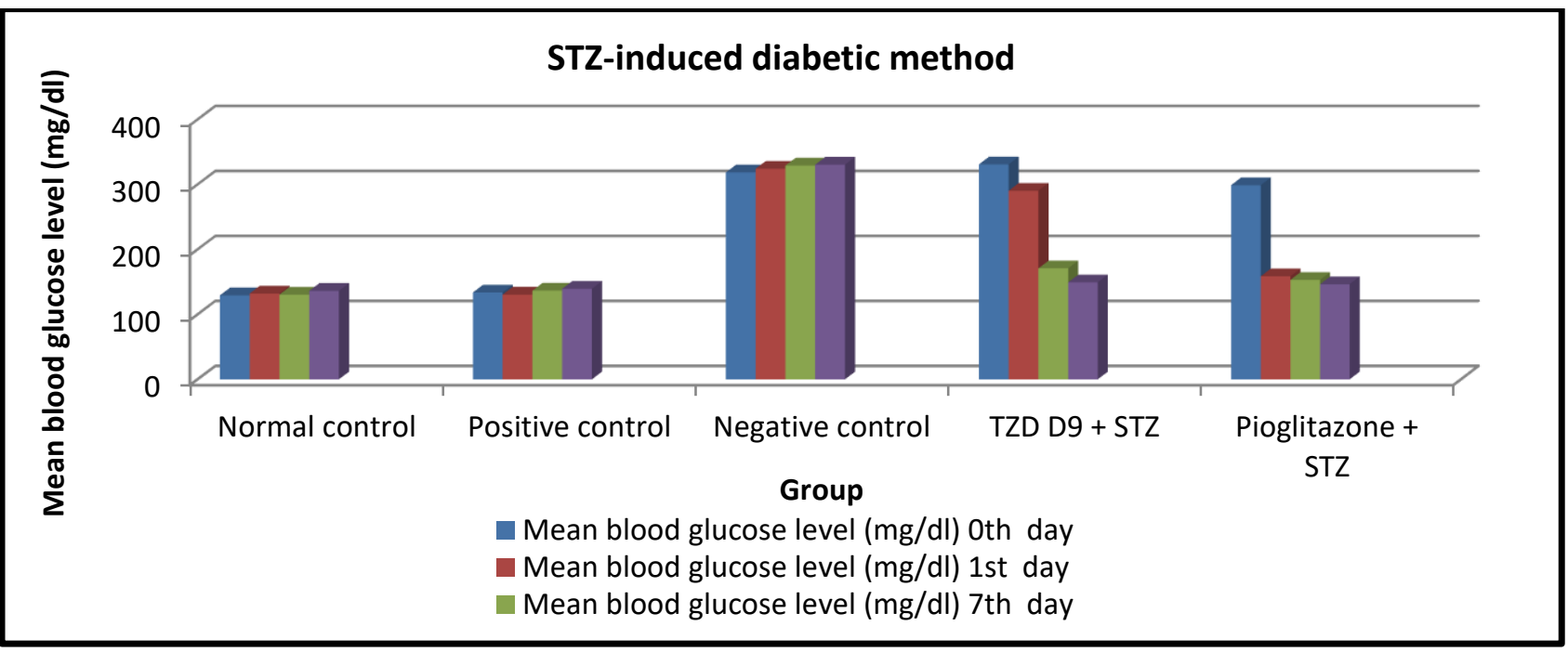

Figure 1: Effect of TZD derivative on blood glucose level in STZ induced diabetic rat

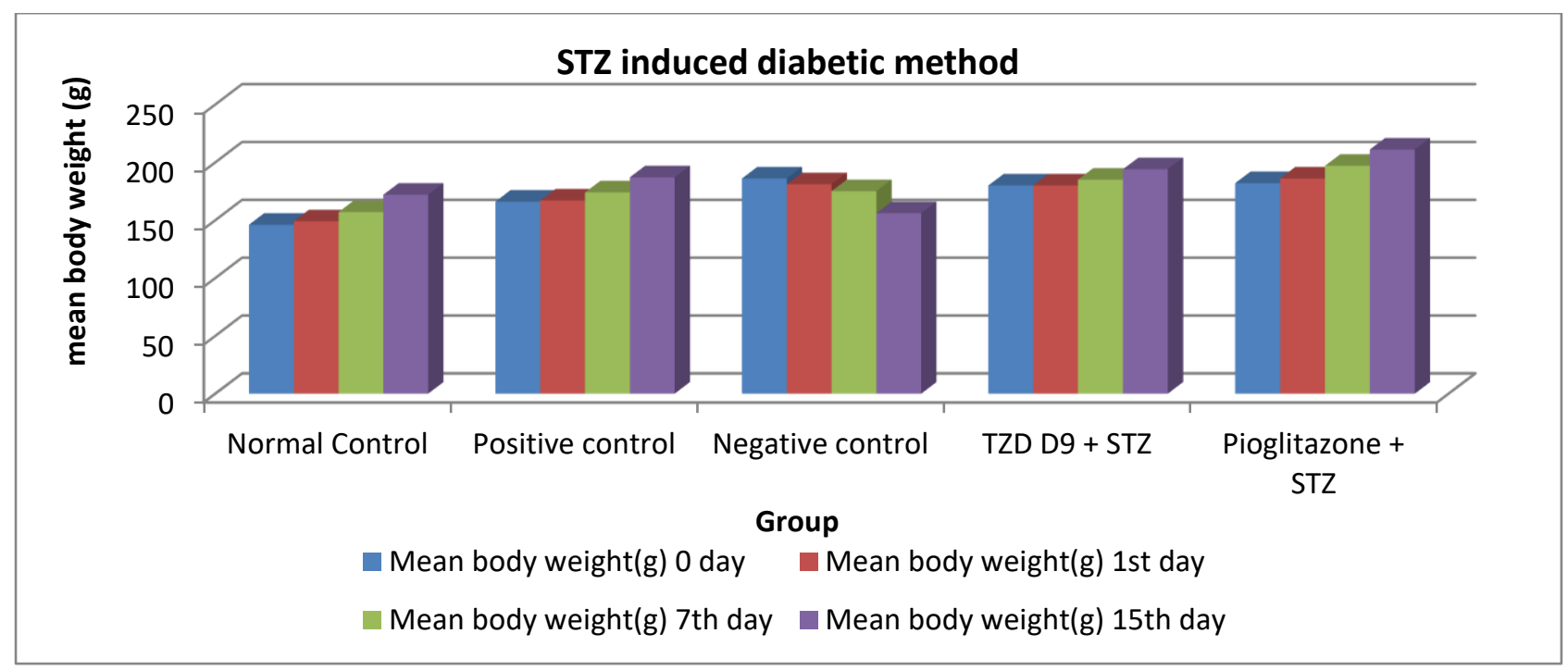

Figure 2: Effect of TZD D9 on body weight in STZ-induced diabetic rats. 


\section{RESULTS AND DISCUSSION}

\section{In vivo antidiabetic activity}

Effect of novel compound on Blood Glucose Level in STZInduced Diabetic Rats.

Blood glucose level of all the animals were recorded as per the study design.

Effect of novel compounds on Body Weight in STZ-Induced Diabetic Rats

Body weights of all the animals were recorded as per the study design. Average weekly body weight of the animal showed a gradual increase in body weight in the animals of all five groups.

\section{CONCLUSION}

The current study found that TZD derivative 4(benzyloxy) benzaldehyde showed highly significant decrease in the blood glucose levels when compared to the control STZ induced diabetic animals which was compared with the standard drug Pioglitazone (36 mg/kg). N- Substituted thiazolidinedione derivative was also found to be safe at the oral dose of $60 \mathrm{mg} / \mathrm{kg}$ body weight in rats.

\section{REFERENCES}

1. Pinheiro DS, Junior EN, Consolini G, Aguiar MJ, Silva RR. Optimized Synthesis and Characterization of Thiazolidine-2, 4-Dione for Pharmaceutical Application. MOJ Biorg Org Chem. 2017;1(4):122-6.

2. Shahnaz M, Bhai PKBR. Synthesis, Characterization of 2 , 4 -Thiazolidinedione Derivatives and Evaluation of Their Antioxidant Activity. Journal of Drug Delivery \& Therapeutics; 2013, 3(6), 96-101.

3. Reddy NS, Sabbani V, Choday V. In vitro and in vivo antidiabetic activity of Rumex vesicarius leaves extract in streptozotocin induced diabetic albino wister rats. Journal of diabetes \& metabolism. 2017 Jun 1;8(6):1824.
4. Naim MJ, Alam MJ, Nawaz F, Naidu VG, Aaghaz S, Sahu $\mathrm{M}$, Siddiqui N, Alam O. Synthesis, molecular docking and anti-diabetic evaluation of 2, 4-thiazolidinedione based amide derivatives. Bioorganic chemistry. 2017 Aug 1;73:24-36.

5. Srivastava AR, Bhatia R, Chawla P. Synthesis, biological evaluation and molecular docking studies of novel 3, 5disubstituted 2, 4-thiazolidinediones derivatives. Bioorganic chemistry. 2019 Aug 1;89:102993.

6. Bhutani R, Pathak DP, Kapoor G, Husain A, Kant R, Iqbal MA. Synthesis, molecular modelling studies and ADME prediction of benzothiazole clubbed oxadiazoleMannich bases, and evaluation of their anti-diabetic activity through in vivo model. Bioorganic Chemistry. 2018 Apr 1;77:6-15.

7. Lee $\mathrm{CH}$, Olson $\mathrm{P}$, Evans RM. Mini review: lipid metabolism, metabolic diseases, and peroxisome proliferator-activated receptors. Endocrinology 2003;144:2201-7.

8. Parulkar AA, Pendergrass ML, Granda-Ayala R, L, Fonseca VA. Nonhypoglycemic effects of thiazolidinediones [published erratum appears in Ann Intern Med 2001;135:307]. Ann Intern Med 2001;134:61-71.

9. Alkali IY. In silico molecular docking studies of some phytochemicals against peroxisome-proliferator activated receptor gamma (PPAR- $\psi$ ). GSC Biological and Pharmaceutical Sciences. 2018;5(2):001-5.

10. Navarrete-Vázquez G, Torres-Gómez H, HidalgoFigueroa S, Ramírez-Espinosa JJ, Estrada-Soto S, Medina-Franco JL, León-Rivera I, Alarcón-Aguilar FJ, Almanza-Pérez JC. Synthesis, in vitro and in silico studies of a PPARY and GLUT-4 modulator with hypoglycemic effect. Bioorganic \& medicinal chemistry letters. 2014 Sep 15;24(18):4575-9.

Source of Support: None declared.

Conflict of Interest: None declared.

For any question relates to this article, please reach us at: editor@globalresearchonline.net

New manuscripts for publication can be submitted at: submit@globalresearchonline.net and submit_ijpsrr@rediffmail.com 